vibration injuries of the hand and arms as part of its series of research papers. ${ }^{8}$ Griffin's useful and comprehensive review looks at the subject from all aspects except the clinical and underlines the lack of real progress in solving several issues. He concludes that the extent of injuries from vibration may be much greater than has yet been documented. Vibration white finger continues to be identified in different groups of workers; for example, in British dockyards $75 \%$ of caulkers and $18 \%$ of chippers are affected. ${ }^{9}$ The report also criticises the setting of standards for limits of vibration-decisions that often seem arbitrary: most standards do not adequately specify the importance of the variables which determine the hazard. Measuring tool vibration is difficult, and test methods need defining. Epidemiological data are often inadequate in published reports and, indeed, may be insufficient to define the variables concerned.

The official British vibration limits published by the British Standards Institution in $1975^{10}$ are still in draft, and although this has given guidance where little was available the report from the Health and Safety Executive is critical on several grounds. The official standard provides an insufficient basis for calculating limits of exposure times, evaluating rapidly changing exposure levels, and summating different exposure levels and durations. The report looks at standards in several other countries, but similar problems are apparentand in particular the lack of adequate physical measurements of exposure to vibration.

Epidemiological data on the direction of vibration, of duration of exposure, temperature, and so on are few, and our ignorance of the pathogenesis of vibration white finger compounds this problem. Moreover, there is even still no general agreement on a theory of causation. In reviewing this subject in $1975^{11}$ we commented that none of the tests then available to assess the function of the nerves and blood vessels could identify a person with vibration white finger; and there are still no satisfactory objective physiological tests. Recently a standardised cooling system of the hand with arterial occlusion has been described, ${ }^{12}$ in which the rewarming time at the fingertips is measured after the hand has been cooled to $10^{\circ} \mathrm{C}$. This procedure is said to be able to distinguish vibration white finger from Raynaud's phenomenon; further studies are planned.

The report from the Health and Safety Executive concludes with a series of 20 recommendations covering the whole range of deficiences in the setting of standards, design of instruments, testing and study of working methods, epidemiological surveys, improvement in the design of tools, and medical investigations into vibration white finger and other effects, including whole-body vibration. Nevertheless, the underlying problems of the vibration syndrome seem as far from solution as ever.

Marshall J, Poole EW, Reynard WA. Raynaud's phenomenon due to vibrating tools. Neurological observations. Lancet 1954 ;i :1151-6.

2 Seppäläinen AM. Nerve conduction in the vibration syndrome. Work, Environment, Health 1970;7:82-4

${ }^{3}$ James PB, Yates JR, Pearson JCG. An investigation of the prevalence of bone cysts in hands exposed to vibration. In: Taylor W, Pelmear PL, eds. Vibration white finger in industry. London: Academic Press, 1975: 43-52.

${ }^{4}$ Taylor W, Pelmear PL, Pearson J. Raynaud's phenomenon in forestry chain saw opcrators. In: Taylor $\mathrm{W}$, ed. The vibration syndrome. London: Academic Press, 1974:121-39.

${ }^{5}$ Industrial Injuries Advisory Council. Raynaud's phenomenon. London: HMSO, 1954. (Cmnd 9347.)

${ }^{6}$ Industrial Injuries Advisory Council. Vibration syndrome. London: HMSO, 1970. (Cmnd 4430.)

Industrial Injuries Advisory Council. Vibration syndrome. London: HMSO, 1975. (Cmnd 5965.)

${ }^{8}$ Griffin MJ. Vibration injuries of the hand and arm: their occurrence and the evolution of standards and limits. London: HMSO, 1980. (Health and Safety Executive research paper No 9.)

${ }^{9}$ Oliver TP, Pethybridge RJ, Lumley KPS. Vibration white finger in dockyard workers. Arh Hig Rada Toksikol 1979;30,suppl :683-93.

10 British Standards Institution. Guide to the evaluation of exposure of the human hand-arm system to vibration. Draft for development. London: British Standards Institution, 1975.

11 Anonymous. Vibration syndrome. $B r$ Med 71975 ;iv : 367.

12 Juul C, Nielsen SL. Locally induced digital vasospasm detected by delayed rewarming in Raynaud's phenomenon of occupational origin. Br F Ind Med 1981;38:87-90.

\title{
Primary care in inner London: inadequate and exposed
}

Britain's inner cities have some of the worst social and medical problems combined with some of the poorest primary care services. ${ }^{1}$ This has been known for a long time, but the problem has taken on a new urgency in London because the two traditional buttresses of primary care, the acute hospital and social services, are now contracting and leaving the inadequate primary care service exposed. Action is needed, and the London Health Planning Consortium (LHPC) Study Group on Primary Health Care in Inner London, chaired by Professor Donald Acheson, has produced recommendations (the important ones are reprinted on p 1814) that it hopes will improve the service considerably within the next five years. ${ }^{2}$ This month has seen also the publication of two other reports that discuss the issues: the Royal College of General Practitioners' report $A$ Survey of Primary Care in London'; and the report of the Joint Working Group on the Primary Health Care Team. ${ }^{4}$ All three agree largely with the comments made on inner London primary care by the Royal Commission on the National Health Service, ${ }^{1}$ and the problem is not one of lack of consensus but of inactivity.
Many of inner London's difficulties are ones about which the National Health Service can do nothing. Compared with the average for England and Wales inner London has more poorer people, more elderly people, more people living alone, more foreigners and immigrants, more single-parent families, more homes lacking basic amenities, generally poorer environmental conditions, and greater population mobility. All of these factors are known to be associated with greater morbidity and mortality, and it is not surprising that, as the Royal College of General Practitioners' report has shown, there are more of such problems as tuberculosis, abortion, admission for mental disorder, and suicide.

Despite the great enterprise and initiative being shown by some inner London general practitioners, the conclusion of these reports is that the primary care services in inner London are inadequate. General practitioners are the most important part of the primary care service, and they are for most people the first point of contact with the whole system of health and social services. Yet many Londoners are not registered with a general practitioner. A study of how many people are not 
registered and why they are not registered is under way at the moment, but the LHPC group reports some small studies that have suggested that between $10^{\circ}{ }_{1}$ and $30 \%$ of people are not registered. Some find it impossibly difficult to get registered: they are turned down by several practices and yet do not understand the family practitioner committee (FPC) system for ensuring inclusion on a list. Moreover, many of those who are registered have great difficulty contacting their general practitioner. A study commissioned by the group showed that $20 \%$ of inner and outer London practices could not be contacted even after three 'phone calls.

Compared with the rest of England and Wales general practitioners in inner London are much more likely to be singlehanded, older, and born overseas. None of these characteristics, of course, necessarily means that the standard of practice is low, but the first two do militate against energetic teamwork, which all of the reports agree is important. Inner London is not actually underdoctored in terms of doctor per head of the population, but many of the doctors have only small lists (6\% have lists under 1000 compared with $1 \%$ in England and Wales). Under the old rules of the Medical Practices Committee, which classified many parts of London as restricted areas with enough doctors, it has been very difficult for younger general practitioners to start practising in inner London. The change of rules on 1 May should be one small step in improving the services, but the LHPC group doubted whether it would be enough.

Further problems are that some inner London general practitioners practise from premises quite unsuitable for modern general practice. Even shabby premises in inner London are very expensive to rent or buy, and rebuilding and repair costs are also considerable. Other important problems are that many London general practitioners do not employ ancillary staff; rely heavily on locums and deputising services; and, according to the reports, spend much of their time in private practice. Moreover, the community nursing services in inner London are understaffed and overworked.

The LHPC group has made 115 recommendations for improving primary care in inner London. Many are points of fine detail, but in a nutshell their philosophy is to try to create in London a primary care service like that which exists in most of the rest of Britain. Thus they want more and younger doctors, more community nurses, more health care teams, better premises, better communications, and more incentives for registering patients and providing a round-the-clock service. Although the group recognises that social and medical problems are more acute in inner London than in most other places, it is confident that a service modelled on that operating in the rest of Britain will be adequate.

Financial incentives for general practitioners to form into groups should be introduced, the group recommends, and there should be disincentives for them to continue practising with small lists. More controversial is the recommendation $\underline{T}$ that there should be a policy of compulsorily retiring general practitioners over 70 and encouraging retirement in those over $\stackrel{\mathbb{Q}}{\varrho}$ 65. If the 106 general practitioners in inner London who are $c$ over 70 were to retire then about 40 vacancies would be created $\widehat{\widehat{O}}$ for younger doctors. The recommendation was made, however, not simply to clear the way for younger doctors but also be- $\mathbb{D}$ cause the group thought that 70 was too old for the demanding m work of general practice. Younger general practitioners, many? of them recently emerged from London vocational training schemes, are available to take up the jobs. The group advocated $\frac{?}{0}$ that FPCs should give more weight to training and potential $\frac{0}{5}$ when appointing new general practitioners. This might mean $\overline{\frac{\sigma}{5}}$ appointing young doctors who have just completed vocational $\stackrel{\nabla}{\Omega}$ training schemes to singlehanded practices. In addition, the group has recommended establishing posts for salaried assis- $\rightarrow$ tants to older general practitioners about to retire; these would $\stackrel{\circ}{\circ}$ then be "heirs apparent."

There are various ways for improving the premises of general $\stackrel{\omega}{\circ}$ practitioners, the group suggests. Minimum standards should

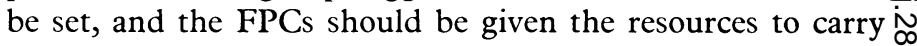
out regular, effective inspections. Furthermore, there should be ? incentives for general practitioners to improve their own pre- N mises, and health and local authorities should be encouraged $\$$ to provide and help with premises. The powers of the General $\vec{v}$ Practice Finance Corporation, which lends money to general practitioners to buy premises, were broadened last year so that $\frac{}{2}$ it could buy premises and lease them to general practitioners, ${ }^{\omega}$ and last week the Government raised its borrowing power from 3 $£ 40 \mathrm{~m}$ to $£ 75 \mathrm{~m} .{ }^{5}$ A good proportion of this money will presumably be used in London.

Professor Acheson's group have made many other recom- $\stackrel{\infty}{-}$ mendations aimed at improving the community nursing service, using the deputising services more effectively, providing more information to the public about how the services work, and raising the morale of the primary care services in London. Many of its recommendations might apply equally well to $\stackrel{\mathbb{Q}}{\Omega}$ other inner city areas in Britain, but the important question $\overrightarrow{\overrightarrow{0}}$ now is will anything happen ? Professor Acheson hopes that the 3 many bodies who have to be consulted will respond quickly and that the sense of urgency set by his group will be maintained. He expects that money will be available to improve primary care in London, and, as he said at the press conference to launch the report, "No money could be better spent."

${ }^{1}$ Royal Commission on the National Health Service. Report. London: $\frac{\mathrm{O}}{3}$ HMSO, 1979. (Cmnd 7615.)

${ }^{2}$ London Health Planning Consortium Study Group on Primary Health $\frac{\mathrm{O}}{2}$ Care in Inner London. Report. London: LHPC, 1981.

${ }^{3}$ Royal College of General Practitioners Working Party. A Survey of Primary o Care in London. London: RCGP, 1981.

4 Joint Working Group on the Primary Health Care Team. Report. London: Department of Health and Social Security, 1981.

${ }^{5}$ Hansard. House of Commons, 18 May 1981, col 124. 